\title{
MEDITECH Health Record System
}

National Cancer Institute

\section{Source}

National Cancer Institute. MEDITECH Health Record System. NCI Thesaurus. Code C105670.

Any of the electronic health record systems and solutions developed by the MEDITECH corporation. 